Old Dominion University

ODU Digital Commons

2014

\title{
Physician as Teacher: Promoting Health and Wellness Among Elementary School Students
}

\author{
Jill E. Stefaniak \\ Old Dominion University
}

Victoria C. Lucia

Follow this and additional works at: https://digitalcommons.odu.edu/stemps_fac_pubs

Part of the Elementary Education and Teaching Commons, Medical Education Commons, Public Health Education and Promotion Commons, and the Service Learning Commons

\section{Original Publication Citation}

Stefaniak, J.E., \& Lucia, V.C. (2014). Physician as teacher: Promoting health and wellness among elementary school students. Education for Health 27(2), 183-187. doi: 10.4103/1357-6283.143785

This Article is brought to you for free and open access by the STEM Education \& Professional Studies at ODU Digital Commons. It has been accepted for inclusion in STEMPS Faculty Publications by an authorized administrator of ODU Digital Commons. For more information, please contact digitalcommons@odu.edu. 


\title{
EDUCATION FOR HEALTH
}

Change in Learning \& Practice

\section{ORIGINAL RESEARCH ARTICLE}

Year : 2014 | Volume : 27 | Issue : 2 | Page : 183--187

\section{Physician as teacher: Promoting health and wellness among elementary school students}

\author{
Jill E Stefaniak ${ }^{1}$, Victoria C Lucia², \\ 1 Instructional Design and Technology, Department of STEM Education and Professional Studies, Old Dominion University, Norfolk, Virginia, \\ USA \\ 2 Department of Biomedical Sciences, Oakland University William Beaumont School of Medicine, Rochester, Michigan, USA
}

\section{Correspondence Address:}

Jill E Stefaniak

Department of STEM Education and Professional Studies, Old Dominion University, Darden College of Education, Room 251-1, Norfolk, VA 23529

USA

\section{Abstract}

Background: Every day, physicians engage in teaching during their patient encounters. It may be that medical students who are introduced to the principles of teaching and learning are more likely to become good communicators and learners. Servicelearning may be an effective way for medical students to practice skills in teaching and communication in a real-world setting, while also filling a need within the community. The purpose of this study was to identify common themes within medical students «SQ» reflections on what they learned through participating in a teaching exercise with local elementary school children. Methods: As a required component of a longitudinal prevention and public health course that spans the first and second years of undergraduate medical education, second year students at the Oakland University William Beaumont School of Medicine, in Detroit, Michigan, in the USA completed a service-learning activity, which included teaching a standardized curricular module to local elementary school children. Students were required to complete a reflection assignment based on their teaching experience. Medical students« $S Q »$ responses to assignment«SQ»S three guided questions were qualitatively coded to identify common themes among the responses related to the teaching activity. Results: Qualitative analysis of students «SQ» reflections revealed several themes regarding what the students learned and viewed as the benefits of the activity: The importance of early education and parental involvement; the importance of understanding your audience when teaching; the importance of simplifying complex concepts to the audience «SQ»S level; and the importance of preparation for teaching. Medical students identified the difficulties of communicating at an audience appropriate level and providing patient education outside the confines of a controlled classroom setting. Discussion: This activity provided medical students with hands-on experience presenting to an audience age-appropriate, health-related topics. Presenting in an elementary school environment helped students better understand what health information various age groups knew about and the importance of clarifying information when communicating with a younger audience.

How to cite this article:

Stefaniak JE, Lucia VC. Physician as teacher: Promoting health and wellness among elementary school students.Educ Health $2014 ; 27: 183-187$

How to cite this URL:

Stefaniak JE, Lucia VC. Physician as teacher: Promoting health and wellness among elementary school students. Educ Health [serial online] 2014 [cited 2016 Dec 5 ];27:183-187

Available from: http://www.educationforhealth.net/text.asp?2014/27/2/183/143785 


\section{Full Text}

\section{Background}

The word doctor in Latin means teacher. Teaching is an activity that all physicians are required to do in a variety of capacities during their career. Introducing the concept of physician-as-teacher to medical students early in their clinical training allows them to begin building their teaching skills early and become more comfortable educating different patient populations. [1] Medical students who are introduced to teaching during their training become better communicators and better learners themselves, as they come to better understand teaching and learning principles. [1],[2]

Educational experiences should be carefully constructed to provide medical students with a variety of learning opportunities beyond the traditional classroom. Medical students should be exposed to a variety of patient populations from varying socioeconomic groups, cultural backgrounds and health challenges. Service-learning has been defined as "a structured learning experience that combines community service with preparation and reflection." [3] Activities that are classified as service-learning must address a community need, be linked to the student's academic coursework, and include a reflective component for the student to make the necessary connections between their responsibility as a citizen and professional in the community in which they serve. Transformative learning in practice can be accomplished with efforts directed toward aligning service and education in order to network with community. Providing medical students with service-learning opportunities within the community places them in authentic learning contexts where they are able to acquire insight into the living experiences of the communities they serve. [4],[5]

Physicians in training need opportunities to reflect on their encounters with patients within their traditional and nontraditional learning environments. Training opportunities that occur outside of the classroom and beyond the traditional, standardized patients allow medical students to gain a better understanding of environmental factors that affect real patients and people in communities, Service-learning introduces physicians in training to the community that they will serve and allows them to experience the perspectives on health and care of the patient, the physician, the healthcare system and the community. By becoming reflective practitioners and experiencing healthcare through multiple perspectives, medical students and residents will be better equipped to address issues that affect all people, including disadvantaged and marginalized populations. [5]

The Promotion and Maintenance of Health course of the Oakland University William Beaumont School of Medicine in Detroit, Michigan, USA, is a longitudinal prevention and public health course that spans the first and second years of undergraduate medical education. During this course students receive instruction on various aspects of prevention and public health, including epidemiology, infectious diseases, nutrition, exercise, and substance use.

As a core component to reinforce the importance of the community approach to healthcare and the importance of communicating with different patient populations, required service-learning activities have been integrated into the curriculum. After receiving a short curriculum on how to teach, medical students teach a health topic to local elementary school students. This aspect of the course was designed to introduce students to teaching and allow them to practice teaching the course's concepts to an audience. Working in small groups, medical students were assigned instructional topics to teach in local area elementary schools.

As an assessment of the "teaching students to be teachers" component of this service-learning curriculum, this study explored students' reflections on its benefits and challenges. The information obtained from this study is intended to improve this and other future educational experiences that required medical students to serve in a teaching capacity within their community.

\section{Methods}

\section{Participants}

A total of 48 second year medical students were enrolled in the Promotion and Maintenance of Health course during the fall 2012 semester. Of the 48 students, 23 were female and 25 were male. Student's age ranged from 22 to 38 years. As part of a service-learning project that was incorporated into the curriculum, students were assigned to 21 teams of 2-3 students each.

Procedures 
The instructors responsible for leading the course coordinated with a local school district in Metro-Detroit and with four of its elementary schools prior to the assignment. The elementary school student body of the district comprised of 58\% Caucasian, $17 \%$ Hispanic, $14 \%$ African-American, $7 \%$ Asian and $11 \%$ bi-racial. Forty percent of students qualified as economically disadvantaged allowing them to receive free meals at school. The average class size was 25-30 students.

Medical students were asked to sign up to teach a standardized curricular module at a local elementary school to fulfill the service-learning requirement. Teachers of grades one through four (6- to 9-year olds) at the local elementary schools agreed to participate if they were interested in medical students coming to their class to deliver a one-hour lesson on a health-related topic. Medical students were provided with a standardized curriculum developed by the Michigan Model for Health curriculum [6] consisting of the following topics: Nutrition and physical activity, personal health and wellness, social and emotional health, and use of alcohol, tobacco and other drugs. Activities varied based on the lesson and grade level.

The medical students had been introduced to the above-mentioned topics as first year students during the first year of the Promotion and Maintenance of Health course. That year, they had the opportunity to engage in service-learning activities, such as health screening events for vulnerable populations. They were also taught strategies for instructional design and patient education within other courses to help them as they engaged in community-based activities.

The Michigan Model for Health curriculum was introduced to students during class time along with the goals of the assignment. Working in small groups of two to three students, the medical students were tasked with delivering a one-hour curricular module. Activities were accompanied by instructor guides and included detailed instructions for lecture materials, games, demonstrations and handouts. The instructor guides provided to students promoted the same instructional strategies that had been introduced in previous training sessions. Students were given the curriculum several weeks in advance allowing them time to clarify any questions with their instructors. Upon completion of the teaching session they led with elementary students, the medical students were asked to complete a reflection assignment based on their teaching experience. The reflection assignment posed the following three questions to the medical student participants:

Question 1: As a physician in training, do you feel it is important to educate a younger audience about such health-related topics? Will this activity help you educate patients in your future practice? Please explainQuestion 2: What did you learn through this experience that was surprising to you or that you did not intend on learning?Question 3: How, if at all, is an activity such as this beneficial to medical students?

This study was approved by the institutional review board at Oakland University for protection of human subjects prior to data analysis. The reflection assignment was a mandatory activity for the course. The assignment was graded as complete or incomplete. Medical students were told in advance that their feedback on the activity, whether positive or negative, was welcomed as the instructors needed to learn from this first time this activity was conducted. Students had participated in servicelearning activities prior to this assignment that involved adults, but this was their first encounter interacting with a pediatric population as well as first time serving as teachers within the community.

\section{Data analysis}

Student reflection assignments were de-identified and students were assigned a participant code. Two researchers independently reviewed the students' responses to the reflection assignment and assigned initial qualitative codes reflecting common responses to each of the three questions posed. The researchers then met to review the initially assigned codes and established a list of common codes that would be used for subsequent analysis. The researchers then independently reviewed the student reflection assignments and assigned the agreed upon codes to each student response. The researchers then reviewed the codes that each had assigned for the individual student comments, and differences were settled through consensus. [7],[8]

\section{Results}

Several themes emerged from analysis of students' responses to the three questions posed in the post-teaching reflection assignment.

\section{Early education and the importance of parental involvement}

After spending time discussing health-related habits, particularly in nutrition, medical students realized that parents need to be included in the educational process as well. Improving health habits in children is more apt to succeed if parents and children 
are approached as a team. Students also realized that it cannot be assumed that parents always make wise choices when it comes to nutrition and other health habits. The students came to believe that it is important to instill these habits in children within their school environment but also important to provide resources for these habits to be carried into the children's homes.

"If we are able to instill healthy related habits into children at a young age, they are more likely to continue these healthy habits into adulthood.... It is also their parents that need education, as the parents are the ones responsible for feeding their children." (Student 11C, 18 and 26)

" I think having us come into the classroom was exciting for the kids and hopefully that will prompt them to go home and teach their parents and siblings...." (Student 4A, 41)

"I think nutrition and exercise education is very important for the younger audience so that they can develop these healthy habits early on and prevent the costly negative health consequences of not exercising and poor eating later on in life...." (Student $11 \mathrm{~B}$, 31)

The importance of understanding your audience

This teaching experience provided medical students with an opportunity to interact and communicate with an audience that was much younger than those with which they had interacted during their encounters with standardized patients and preclinical classmates. Reflection responses shed some light on the students' previous misperceptions regarding a child audience. Medical students were surprised by how excited the children were to have them in their classroom and how highly engaged they were during the activities.

"I was not expecting them to really know the answers to some of our questions but they were better educated and smarter than I thought they were. I learned that I shouldn't underestimate my audience." (Student 11C, 31)

"I did not expect the children to be so eager in wanting to learn.... I believed that young children do not want to do any form of work aside from that given by their teacher." (Student 12A, 34)

"I did not expect that a topic that seemed so simple to me would be so complicated to someone else." (Student 1C, 29)

Needing to simplify complex concepts

During this teaching experience, medical students also quickly learned the importance of simplifying information to an appropriate level for their audience by using simpler words and stressing only the key concepts. Students quickly came to realize that they need a good understanding of their audience's capabilities when communicating educational materials to them.

"We really had to simplify everything we were teaching which is much harder said than done.... I think this experience was a great opportunity to practice "living room" talk." (Student 4A, 47)

"One thing I learned during this experience was how difficult it is for me to speak to people with a much lower education level." (Student 4B, 46)

Good preparation for teaching patients

Students reflected that they recognized the value of this type of teaching exercise for medical students. This exercise reminded students that there is a person at the receiving end of every conveyed diagnosis and that education will be incorporated in almost every patient interaction in their careers. In addition, the experience allowed students to discover for themselves, in a non-intimidating environment, how difficult it can be for a patient to understand a physician and how difficult it can be for physicians to verbally educate patients.

"It put us into a situation that was out of our "comfort zone" that we had to react to, while thinking on our feet. During our education and when we become physicians, we will be in a constant state of learning and teaching." (Student 21B, 131)

"I think this experience was enormously beneficial to us as medical students because it underscores that teaching is an important aspect of being a physician." (Student 19B, 65)

"I also think it helps medical students connect with their community and remember why we are in medicine." (Student 17B, 70)

"We need to be able to explain ideas to a diverse population." (Student 11A, 31) 
"I was a bit confused as to the relevance in our training, however, when we were preparing for the class I realized it was a great opportunity to practice speaking in common everyday language.... Speaking to patients in terms they recognize is paramount to their understanding their diagnosis and adhering to their treatment...." (Student 4B, 34)

\section{Discussion}

This activity provided medical students with hands-on experience presenting to an audience health-related topics at an ageappropriate level. Presenting in an elementary school environment helped the medical students better understand what different age groups know about health and the importance of presenting information at the right level when communicating with a young audience. As future physicians, it is important for medical students to learn how to talk about health issues with patients and other audiences who are at a variety of levels in their understanding of health. [2]

This service-learning program described here faced a few programmatic challenges. It was difficult finding enough elementary teachers and classrooms to participate in the project to accommodate the size of our medical class. We found it be helpful to partner with a local school district, as it provided us access to multiple schools that were held to the same curricular standards. Utilizing the state-approved curriculum helped us gain permission from the schools to deliver the curriculum and also made teaching more convenient for the medical students.

The varying backgrounds of the medical students posed challenges for the instructors organizing this project. While the students had been exposed to the same curriculum during medical school, there were a few students who had previous experience working with children in a volunteer capacity. There were a few students who also had previous experience as school teachers or tutors and were familiar with instructing children. Due to the small sample size of participants, the instructors were familiar with the students and their backgrounds and tried to assign those who had previous teaching experience with others who did not.

We also observed that not all medical students dedicated the same amount of time in preparing for their class. While some groups spent several weeks preparing and communicating with instructors, others chose to prepare just a day or two in advance. We would recommend that others dedicate a class session to preparing materials so that the instructors could be present to answer any questions from students. This could also help prevent students from delaying their preparation as well as provide instructors with the opportunity to provide formative feedback to assist the medical students with their instructional delivery.

\section{Study limitations}

There are two limitations attributed to this study. The student reflections were submitted as an assignment requirement for the service-learning activity and, therefore, were not anonymous. The instructors de-identified the reflections and assigned the students participant codes to eliminate any researcher bias. Students were asked to provide the instructors with honest feedback and were told that any negative feedback they provided regarding the assignment would not affect their grade. While most student reflects appeared to be honest, consisting of positive and negative constructive criticism, there is a possibility that some students may have been reluctant to reveal all of the challenges that they had experienced during the activity.

A second limitation associated with this study is that the reflections that were qualitatively coded and analyzed were selfreported reflections of the students' experiences in the classroom. Further validity could have been given to their self-reflections had the instructors observed every teaching session to confirm the behaviors and experiences shared in the self-reflections. Observational analysis could have identified additional successes or challenges that the medical students may not have recognized. Further studies addressing medical student's experiences in the classroom would benefit from triangulating data sources by utilizing medical student self-reflections, observational analysis, and assessment of the learning audience.

\section{Conclusions}

Service-learning is a method of learning that allows students to develop in their personal efficacy, sense of morality, social responsibility, critical thinking and civic engagement, while building bridges to communities and filling their needs. [1],[9] Medical students expressed that they found this exercise was important to their training because it exposed them to a demographic group to which they otherwise have little exposure within the curriculum. In addition, it allowed students to apply foundational knowledge and practice doctoring skills acquired in the classroom setting and with standardized patients. This exercise also allowed the medical school to connect with and develop a relationship with a local school district. It also met the elementary school's need for nutritional and health education within the curricular standards set by the state of Michigan. [6] This activity was 
positive and beneficial for both medical students and the community.

Students reported that it was more difficult to simplify concepts for their young audience than they had expected. Based on the themes extracted from student reflections, it is evident that the medical students were able to see the educational and personal benefits that this activity had on their training. It is important for medical students to be versatile in how they approach patient education; service-learning exercises can help strengthen their communication skills and confidence in educating diverse populations.

\section{References}

1 Dandavino M, Snell L, Wiseman J. Why medical students should learn how to teach. Med Teach 2007;29:558-65.

2 Stefaniak JE, Baaki J. A layered approach to understanding your audience. Perform Improv 2013;52:5-10.

3 Liaison Committee on Medical Education. Functions and Structure of a Medical School: Standards for Accreditation of Medical Education Programs Leading to the M.D. Degree. Available from: http://www.lcme.org/publications/functions.pdf. [Last accessed on 2013 Aug 21].

4 Butin DW. Service-learning in theory and practice: The future of community engagement in higher education. New York: Palgrave Macmillan; 2010.

5 Dogra N, Reitmanova S, Carter-Pokras O. Twelve tips for teaching diversity and embedding it in the medical curriculum. Med Teach 2009;31:990-3.

6 Education Materials Center. Michigan Model for Health. Available from: http://www.emc.cmich.edu/mm/. [Last accessed on 2013 Nov 10].

7 Lincoln YS, Guba EG. Naturalistic inquiry. Newbury Park, California: Sage Publications; 1985.

8 Willig C. Introducing qualitative research in psychology: Adventures in theory and method. 2 nd ed. Maidenhead, England: McGraw Hill/Open University Press; 2008.

9 Richey RC, Klein JD, Tracey MW. The instructional design knowledge base: Theory, research, and practice. New York: Routledge; 2011. 